\title{
Urinary incontinence after treatment for prostate cancer
}

In this editorial by Ruth Doherty and Zaki Almallah (BMJ 2011;343:d6298, doi:10.1136/bmj.d6298), the second author should be Y Z Almallah.
Cite this as: BMJ 2011;343:d7850

๑ B BMJ Publishing Group Ltd 2011 